\section{Kitap Tanıtımı}

ISSN 2548-0502

\title{
Türk Edebiyatı Tarihine Bir Katkı Olarak
}

\section{Modern Türk Edebiyatı}

\author{
ARŞ. GÖR. SERCAN CEYLAN*
}

\section{MO.DERN $\underset{\text { EDEBIYATI }}{\mathrm{TU}}$} OKTAY YIVLI

MUHARREM DAYANC BEDİA KOCAKOĞLU OKIAY Yivil.

MAKSUT YIG̈ITBAS

DIIPFM ARIDAIII BÜYÜJKARMAN

YASEMIN MUMCL

MLRAT KACIROĞLU

MAHMI T BABACAN

SEVIM SERMET

SFI.AMI AI.AV
21. yüzyıla gelinceye değin Türk Edebiyatı tarihiyle ilgili pek çok çalışma ortaya konmuş ve bunlar büyük oranda yazarlarının yöntemsel, biçimsel ya da düşünsel tercihlerine bağlı kalarak didaktizmi hedefliyor görünmüşlerdir. $\mathrm{Bu}$ çalışmalar edebiyat, dil ve kültür zincirini ilerletmek, tanıtıcı ve açıklayıc bilgileri okur için bir drajeye dönüştürmek ve edebiyat eğitimi bakımından derli toplu bir kaynak olmak görevlerini üstlenirler. Dil devrimi öncesinden, Abdülhalim Memduh'un Tarih-i EdebiyatOsmaniye'sinden başlayarak özgül bir disipline kavuşan edebiyat tarihçiliğinin genellikle 20 . yüzyılda devinime kavuştuğunu görüyoruz. Klasik edebiyatta vücut bulan tezkire geleneğinin bir tetik, bir omurga göreviyle Tanzimat ve sonrası edebiyat tarihçiliğine destek olduğu da unutulmamalıdır. M. Orhan Okay, TDV İslam Ansiklopedisi'ndeki "Edebiyat Tarihi" maddesinde bu alanı kavramak ve alanda eser veren çalışmaları genel olarak görmek bakımından önemli bilgiler verir. Fakat yazıda ne yazık ki ancak Agâh Sırrı Levent'in Türk Edebiyatı Tarihi'ne (1973) kadar gelinebilmiştir. Ahmet Hamdi Tanpınar'ın 19. Asır Türk Edebiyatı Tarihi ve daha sonra Kenan Akyüz'ün Modern Türk Edebiyatı'nın Ana Çizgileri ve bir dereceye kadar Nihat Sami Banarlı'nın Resimli Türk Edebiyatı Tarihi ise edebiyat tarihleri arasında en rağbet görenleridir. Özellikle akademik çevrede şöhretleri oldukça geniş bir alana yayılmıştır. Bunların dışında edebiyat tarihi denince

\footnotetext{
* Balıkesir Üniversitesi, orcid.org/0000-0003-3093-2741, sercan.ceylan@hotmail.com Gönderim tarihi: 12.03.2018

Kabul tarihi: 18.05.2018
} 
yirminci yüzyılın sonlarından günümüze Şükran Kurdakul'un dört ciltlik Çă̆daş Türk Edebiyatı, İnci Engin'ün Yeni Türk Edebiyatı Tanzimat'tan Cumhuriyet'e (1839-1923) ve Cumhuriyet Dönemi Türk Edebiyatı adlı eserleri akla gelir. Kısmi şekilde birden fazla yazar tarafından Tanzimat, Servet-i Fünun ve diğer dönemler üzerine edebiyat tarihi çalışmalarının yapıldığı da görülmektedir. Günümüze gelindiğinde edebiyat tarihlerinin akademik ve eğitsel yön açısından en revaçta olanı, şemsiyesini Tanzimat döneminden günümüz şair ve yazarlarına kadar genişleten Yeni Türk Edebiyatı El Kitabı (1839-2000) gibi görünmektedir. Bundan başka, 2014 yılında, Atatürk Kültür Merkezi'nde düzenlen Türk Edebiyatı Tarihi Yazımı Çalıştayı bu alanda önemli konulara değinmesi ve bir farkındalık yaratması bakımından dikkate değerdir. Bütün bu kısa bilgi ve açıklamaların ardından şunu fark ediyoruz; Türk edebiyatında oluşturulacak yeni bir edebiyat tarihi için gerekli deneyimi pekâlâ sunabilecek verimli bir veri kaynağı vardır ve bu kaynak araştırmacıların ilgisini beklemektedir. Modern Türk Edebiyatı'ndan** söz açmadan önce kültürel refleksin gerginliğini almak adına bu açıklamaları yapmanın faydası vardır. Bu sayede edebiyata temkinli bir saygı besleyen okura bir sinopsis ya da tanıtım sunmak için ayrıntılara değinmek epey kolaylaşır. Elbette böyle bir okur kitlesi "kültürel refleks" değil "kültürel farkındalık" geliştirmiştir ve kim ne derse desin Sezar'ın hakkı Sezar'a diyecektir. Kitaplar insanları sonsuza kadar kandıramaz. Bunun tersi de geçerlidir.

Oktay Yivli'nin editörlügüunde, alanında uzman on yazar tarafından kaleme alınan Modern Türk Edebiyatı, edebiyat tarihçiliğine dair bütüncül bir çerçeve çizerek alana gerekli ilgiyi göstermiş denebilir. Bu çalışma, nitelikli ve akademik bir referans kitap olmak üzere yola çıkmıştır. Türk edebiyatı tarih yazıcılığına özgül bir katkı sunmayı da hedefleyen eserin elbette didaktik bir kaygı taşıdığı ve bu bakımdan da bazı tercihler yaptığı anlaşılmaktadır. Mesela doğrudan "Modern” edebiyata işaret etmesinin belirli sebepleri vardır. İçerikte bu sebepleri somut olarak sezmek mümkün. Bütününe bakıldığında ise Modern Türk Edebiyatı yirminci yüzyılın bitişine değin bir edebiyat tarihi ortaya koyarak araştırmacı ve meraklıların kolayca yararlanacağı referans bir kitap haline gelmiştir.

Ortak paydalarda buluşsalar da bölüm yazarlarının her biri, kendilerine ayrılan konularda belirledikleri ölçütlere göre hareket eder. "Tanzimat Dönemi Edebiyatı I" başlığ altında Muharrem Dayanç ve Selami Ayan'ın Tanzimat dönemindeki sosyal ve siyasal olaylardan bahsettikleri kısımla döneme genel bir giriş yapılır. 1839'da Tanzimat Fermanı'yla birlikte hızlanan modernleşme hareketleri, büyük oranda Lale Devri'ne dek uzanmaktadır. Dolayısıyla yazarlar bu ve sonrası dönem devlet politikaları, özellikle eğitim ve kültür hayatındaki değişikliklere değinirler. Burada Tanzimat Dönemi ana hatlarıyla dört başlıkta özetlenmiştir: "Tercüme Heyeti", "Yirmisekiz Mehmet Çelebi Efendi'nin Paris

\footnotetext{
** Yivli, Oktay (Ed.) (2017). Modern Türk Edebiyatı. İzmir: Günce Yayınları.
} 
Sefaretnamesi", "Matbaa" ve "Askerlik Alanında Yapılan Yenilikler." Bu alt başlıkların ardından Tercüme Odası (1821) ve Encümenidaniş (1851) kurumlarının önemi açılanır. Tarihi mekânların da yenileşmeye katkıları değerlendirilir. Mesela Ahmet Vefik Paşa, Mithat Paşa, Fuat Paşa, Mahmut Nedim Paşa ve Ziya Paşa gibi birçok entelektüel, düşünür, yazar ve devlet adamı Mustafa Reşit Paşa'nın konağında buluşmuşlardır. Batı etkisiyle edebi ve kültürel değerlerin sınandığı Tanzimat dönemi şiirinin öncüleri olarak ise Keçecizade İzzet Molla, Akif Paşa ve İbrahim Şinasi Efendi kabul edilir. Burada Modern Türk Edebiyatı'nın özgün bir yönü olarak psikanalitiği kullanışına değinmekte yarar var. Şinasi'nin Reşit Paşa'ya yazdığı "Kaside” psikanalitik açıdan -id, ego ve süperego unsurları belirlenipincelenerek gönül, akıl, söz ögelerinin ilişkisi değerlendirilmiştir. Şiir doğrultusunda dönemin düşünsel ve politik atmosferini anlamak için Namık Kemal'in "Hürriyet Kasidesi" şiirinin tam metni verilir. Yine Türk edebiyatında eleştiri türünün ilk örneklerinden olması bakımından, Ziya Paşa'nın 1868'de yayımladığ 1 “Şiir ve İnşa” makalesi değerlendirildikten sonra onun da tam metnine yer verilmiştir. Bu iki alıntı, devrin orijinal söylemine tanıklık etmek bakımından önemlidir. Klasik edebiyat etkisini daima yakınında hisseden modern şiirin sürekliliğini görmek bakımından "nazire" türüne ayrı bir başlık açılmıştır. Nitekim Ziya Paşa, Namık Kemal gibi şairler için iyi şiire geçişte nazire yazmak kaçınılmazdır. Bir başka önemli nokta da Ahmet Mithat Efendi'nin romanlarını kapsayan tasniftir. Yazarın romanları içerikleri bakımından "Aile romanları", "Tarihi romanlar", "Macera romanları", “Biyografik romanlar" ve “Osmanlı Devleti'ndeki çeşitli kavimlerle ilgili hikâye ve romanlar" olmak üzere beş başlığa ayrılır. Tanzimat döneminin birinci evresi ele alınırken özellikle tiyatronun gelişimi ve tiyatro metinlerinin içerikleri hakkında açıklayıcı bilgiler verilmiştir. Metni kuru bir edebiyat tarihçiliğinin yüzeyselliğinden kurtaran bu kısımlarda okura doğrudan eserlerin konusu, kurgusu ve belli başlı olayları tanıtılır.

Tanzimat döneminin ikinci evresinde Recaizade Mahmut Ekrem, Abdülhak Hamid Tarhan ve Muallim Naci odağa alınır. Sevim Şermet, “Tanzimat Dönemi Edebiyatı II” başlığı altında öncelikle şiire değinir. Abdülhak Hamid'in Türk şiirine ve Modern Türk edebiyatına katkılarından bahsedildikten sonra şairin edebi kişiliğiyle özdeşleşen "Makber" şiiri tahlil edilir. Tahlilde hem içerik hem de biçim açısından biyografik ve sosyolojik verilerin kullanıldığı görülmektedir. Bu tespitler, Abdülhak Hamid'in şiir dünyasını aydınlatıcı önemli ipuçları içerir. Hikâye ve romanlar ise Recaizade Mahmut Ekrem ve Samipaşazade Sezai'nin edebi kişilikleri etrafında incelenmiştir. Tanzimat dönemi tiyatroları anlatılırken Recaizade Mahmut Ekrem ve özellikle Abdülhak Hamid'in eserleri üzerinde durulur. Bu kısımda Muallim Naci ve onun eserleri birkaç cümleyle özetlenmiştir. Eleştiri türü incelenirken yöntem ve değerlendirmeler açısından Bilge Ercilasun'un Servetifünun'da Edebi Tenkit adlı eserinden yararlanıldığı görülür. Şermet'in kendi üslubunun ürünü olan özgün 
değerlendirmeler ise var olan çalışmalara yenilikçi bir katkı niteliğindedir. Konunun sonunda ise örnek metinlere yer verilmiştir. Recaizade'nin Araba Sevdası romanından örnek olarak, Çengi ve Periveş Hanımların Bihruz Bey hakkında sohbet ettikleri bir bölüm alınmıştır. Samipaşazade'nin "Küçük Şeyler" öykü kitabındaki "Kediler" öyküsü, Abdülhak Hamid'in Sabr u Sebat oyunundan bir parça ve son olarak Recaziade Mahmut Ekrem'in Takdir-i Elhan adlı kitabından şiirin konusunun ve tarifinin ele alındığı bir kısım, diğer örnek metinlerdir.

Mahmut Babacan'ın kaleme aldığı "Ara Nesil Edebiyatı I" adlı bölümde 1885 yıllarında çoğunluğu oluşturan Ara Nesil sanatçıları ele alınır. Bunlardan kırk bir tanesinin adı anıldıktan sonra edebi yetkinlik bakımından önde gelenlerinin şiir, roman, öykü, eleştiri ve tiyatro hakkındaki görüşlerine yer verilir. Eserlerinden bazıları hakkında ayrıntılı açıklamalar yapılır. Bu bölümde Ara Nesil sanatçılarının Türk edebiyatına getirdiği yenilikleri, takip ettikleri edebi anlayışı detaylı şekilde görmek mümkün. Dikkat çeken bir nokta, yazarların görüşleri yansıtılırken doğrudan o dönem dergi ve gazetelerine işaret edilmesi, alıntıların birincil kaynaktan yapılmasıdır. Konu bitişinde verilen örnek iki metin, Mehmet Celal'in "Görünmüyor!" şiiriyle Ali Kemal'in “Öyle De Yazılabilir Böyle De" şiiri, dönemin sanat anlayışını -şiiri merkeze alarak- kavramaya kolaylık sağlamaktadır. Bölüm yazarı, bu metinler üzerinde açıklayıcı değerlendirmeler yapar. Hatta Mehmet Celal'in şiiri pek çok yönden tahlil edilir.

Modern Türk Edebiyatı, Ara Nesil'i de geçerek tarihsel çizgiyi Servetifünun edebiyatıyla devam ettirir. Maksut Yiğitbaş tarafından yazılan "Servetifünun Edebiyatı"nda, bu dönem Türk edebiyatına damgasını vurmuş sanatçılar başat kabul edilir ve şiirde ağırlıklı olarak Tevfik Fikret ve Cenab Şahabettin üzerinde durulur. Yiğitbaş, Fikret ve Cenab'in şiir anlayışları hakkında referans bilgiler vererek kendi bakış açısıyla değerlendirmeler yapar. Fikret ve Cenab'ın dışında Ali Ekrem, Hüseyin Suat Yalçın, Faik Ali Ozansoy, Hüseyin Siret Özsever olmak üzere dört şairin daha sanat ve edebiyat anlayışlarına yer verir. Servetifünun roman ve hikâyesinden bahsedilirken Mehmet Rauf ve Halit Ziya odağa alınır. Halit Ziya'nın Mai ve Siyah romanı üzerine tarihsel ve sosyolojik verilerin de dikkate alındığı ayrıntılı bir tahlil yapılmıştır ve tahlil hem estetik hem de didaktik bir özellik taşır. Eleştiri türüne gelindiğinde ise dönemin edebiyat çevrelerine adını duyuran "Dekadanlar" polemiği ve Klasikler tartışması ele alınmıştır. Bu kısımda Servetifünun eleştirmenleri olarak Ahmet Şuayp, Cenap Şehabettin ve Hüseyin Cahit üzerinde durulur. Cenab Şehabettin'ın "Evrakıeyyam" kitabından örnek seçilen “Oğluma Altıncı Mektup" metni ise okura Cenab'ın sanat anlayışı hakkında fikir verir. Onun bu metindeki eleştirileri, kendisinin ve neredeyse Servetifünun edebiyatçılarının şiir, kafiye, vezin, sanat vb. hakkındaki düşüncelerini yansıtmaktadır. Ayrıca bölümün yazarı tarafından bu metin etraflıca değerlendirilir. 
“II. Meşrutiyet Dönemi Edebiyatı" başlığı altında Yasemin Mumcu, dönemin tarihi ve sosyal çerçevesini ortaya koymakla işe başlar. Edebiyat ve kültür hayatına yoğun olarak etki eden II. Meşrutiyet'in tarihi ve sosyal olayları genel hatlarıyla açıklandıktan sonra Batıcılık, Osmanlıcılık gibi düşünce akımlarına değinilir. Siyasal zeminde krizlerin yaşandığı bu evrede edebiyat, özellikle şiir aracılığıyla soluk alabilmiştir. Bu yüzden devrin edebiyatçıları işlenirken ağırlıkla olarak şairler incelenmektedir. Mehmet Emin Yurdakul'ın Türkçe Şiirler'inden (1899) başlanarak Fecriati, Milli Edebiyat ve diğer topluluklara değinilip kronolojik olarak Dergâh (1921) mecmuasına kadar varan II. Meşrutiyet şiirinin iskeleti çıkarılır. Bunun yanında doğal olarak roman ve hikâye yazarları oldukça sınırlı bir çerçevede sunulmuştur. Yine tiyatro, tenkit, mizah ve hiciv türlerinin şiire göre oldukça az rağbet gördüğü belirtilerek yaşanan "edebi durgunluk” ve bu durgunluğun genel sebepleri belirlenmiştir. Örnek metinlerden Ahmet Haşim'in "Çöller" şiiri içerdiği imgeler ve ahengi sağlayan biçimsel ögeler bakımından incelenirken Ömer Seyfettin'in Efruz Bey romanındaki "Hürriyete Layık Bir Kahraman" hikâyesi değerlendirilmiştir. Örnek olarak yalnızca metinlerin verilmemesi, bu metinlere dair bilinçli tespitlerin yapılması estetik farkındalığın yanında eğitsel bir fonksiyonu da yerine getirmektedir.

Diğer dönemlerle kıyaslayınca Cumhuriyet dönemi Türk edebiyatı daha ağır, yani şair, yazar ve ürünler bakımından daha kalabalıktır. Bu yüzden şiir, roman, öykü, tiyatro ve diğer türler olmak üzere beş bölüme ayrılarak anlatılır.

Oktay Yivli, “Cumhuriyet Dönemi Türk Şiiri”ni ele aldığ1 bölümünde edebiyat tarihlerindeki klasik tasnifleri benimser görünür. "Memleketçi Şiir" başlığ1 altında Faruk Nafiz'den Bedri Rahmi Eyüboğlu'na toplam yirmi şaire değinir. “Öz Şiir" anlayışını takip eden Yahya Kemal ve Ahmet Haşim'den Behçet Necatigil'e dokuz şair öz biçimde tanıtılır. Ardından 1980'lere değin Türk şiirindeki kırılmaların tarihçesi verilir. Pek çok şairin başat yönleriyle yansıtılabilmesi için konuya dair kapsamlı referanslara göndermeler yapılır. 1980 ve 1990 kuşağı olarak ikiye ayrılan "Son Dönem Şiiri” hakkında sunulmuş kısa fakat tanıtıcı bilgiler dolayısıyla neredeyse günümüze varan bir Cumhuriyet dönemi Türk şiiri ortaya konulmuştur. Cumhuriyet dönemi şiirinin önceki dönemlere göre pek çok isim tarafından temsil edilmesi tarih yazımı için zorlayıc bir unsur sayılabilir. Bundan olacak ki Yivli, şairleri incelerken ansiklopedik bir tavır takınır. Her şairin eğitim ve çalışma hayatındaki elzem noktalar üzerinde durduktan sonra birkaç cümleyle sanat anlayışını özetleyip eserlerine yer verir. Yivli'nin yaklaşımı yöntem bakımından Modern Türk Edebiyatı yazarlarına göre daha öz ve ansiklopedik bir görünüm kazanmıştır.

Bedia Koçakoğlu, “Cumhuriyet Dönemi Türk Romanı”nda tematik değil kronolojik bir sinıflandırma yapar. Yazar, Cumhuriyet romanın 1923-1950 arası, 1950-1980 aras1, 1980 sonrası postmodern dönem olmak üzere üç evreye ayırmaktadır. Bu bölümde Halide Edib 
Adıvar ile Yakup Kadri Karaosmanoğlu'ndan başlanarak Cumhuriyet dönemi romancıları ve onların edebi kişiliklerini yansıtmak bakımından önde gelen eserleri ele alınmıştır. İlk evrede, 1923-1950 yılları arasında eser veren romancılar kendi içlerinde tekrar sınıflandırılır. “Dönemin Sosyal Tanıkları”, "Ferdi Konulara Yönelenler”, “Popüler Romancılar”, “Maziden İlham Alanlar", “Toplumcu Gerçekçileri Hazırlayanlar” başlığı altında bu yazarların edebi kişilikleri işlenir. İkinci evrede, 1950-1980 arası roman da belirli başlıklara ayrılmıştır. “KöyKöylü Konusunu İşleyenler", "Tarihi Konulara Eğilenler", “Toplumsal Konulara Yönelenler", "Bireysel Yönelimler", “Mizahı Romana Taşıyanlar", “Postmoderne Geçişte Kırılma Evresi" olarak belirlenen ayıklamadan sonra romanciların edebi portresi ortaya konulur. Son evre ise 1980 sonrasını kapsamaktadır. Burada 1980 ve sonrası eser veren romancılar tematik ve teknik açıdan yeniden ayrıma tabi tutulur. "Toplumsal Konulara Yönelenler”, “İslami Söylem Taşıyanlar”, “Tarihi Konulara Eğilenler”, “Bireysel Yönelimler”, "Fantastik Kurgu Eğilimleri”, "Popüler Romancılar”, "Kadın Sorunlarına Dikkati Çekenler” ve "Postmodernist Anlatı Yazarları." başlıkları altında romancılar hakkında bilgi verilir. Bölümün sonunda Hasan Ali Toptaş'ın Kayıp Hayaller Kitabı romanına dair esaslı bir inceleme yer almaktadır. Yaklaşık on bir sayfalık bu incelemede karakter, olay, anlatıcı, mekân gibi pek çok öğenin estetik ve didaktik bir tonda, ayrıntılı bir değerlendirmesi yapılmıştır.

Murat Kacıroğlu “Cumhuriyet Dönemi Türk Öyküsü”nü üç evrede ele alır. İlk evre “1923-1950 Arası Türk Öykücülüğü” olarak belirlenmiştir. İkinci evre “1950-1980 Arası Türk Öykücülüğü” ve üçüncü evre “1980 Sonrası Türk Öykücülüğü” adını alır. Bu başlıklar altında öykücülerin sanatları ve eserleri hakkında bilgi verilir. Kacıroğlu, kitaptaki diğer yazarlardan farklı olarak sayfa altı dipnot yerine satır arası dipnot yöntemini tercih etmiştir.

“Cumhuriyet Dönemi Türk Tiyatrosu” Didem Ardalı Büyükarman tarafından kaleme alınmıştır ve bu dönem, öykü ve romanda yapıldığı gibi üç evreye ayrılır. “ilk Evre 19231950”, “İkinci Evre 1950-1980” ve “Üçüncü Evre 1980 Sonrası” şeklinde tiyatroya dair geniş bir panorama çizilir. Büyükarman, tiyatro türünü incelerken geleneksel Türk tiyatrosundan modern tiyatroya geçiş sürecini, iktidar ve devlet tiyatroları ile oyuncu ve oyun yazarlarının kültürel, tarihsel ve sosyal durumunu ortaya koyar. Bu doğrultuda değinilen üç evrede de "Mekânlar ve Topluluklar" ile "Oyun Yazarları ve Piyesler" üzerinde durulur. Bölümün sonunda Murathan Mungan tarafından kaleme alınan Taziye oyunun yaklaşık dört sayfalık bir tahlili yer almaktadır.

Modern Türk Edebiyatı'ndaki son bölüm “Cumhuriyet Dönemi Kurmaca Dışı Türler"e ayrılmıştır. Mahmut Babacan bu bölümde eleştiri, deneme, gezi yazısı, anı, günlük/günce olmak üzere beş edebi türü odağa almaktadır. Söz konusu türler hakkında genel bir çerçeve çizdikten sonra bu türlerde eser vermiş önde gelen yazarların, yaşamöykülerinden de 
yararlanarak, edebiyat anlayışlarını ortaya koymuştur. Öykü, roman, şiir vb. kurmaca türlere kıyasla eleştiri, deneme gibi türlerin oldukça dar bir alanı kapsadığı görülmektedir. Bu istatistiksel çıkarım, Türk edebiyatını daha yakından okumak isteyen okura somut bir karşılaştırma imkânı verir.

Sonuç olarak bu yazıda, bir Türk edebiyatı tarihi olarak Modern Türk Edebiyatı'nın içeriği hakkında fikir verici ayrıntılardan bahsedilmiştir. Şimdiyse sonuç yerine küçük notlardan bahsedip biraz olsun yazının ciddiyetini dağıtmak yararlı olacaktır. Mesela merak uyandıran konu; neden bir edebiyat tarihi yazılmak istenmiş, diğerleri neden eksik sayılmış ve neden bu esere "Modern" yakıştırması uygun görülmüş, bunlar okurdan elini taşın altına koymasını bekleyen yalnızca birkaç soru. Octavio Paz'dan alıntılarla modern bir değerlendirme ya da psikanalitik bir şiir incelemesi buna cevap olabilir mi, bir ihtimal. Ancak bu çalışmanın Türk edebiyatı tarihi yazıcılığına özgül bir yorum getirdiği açı. Türk edebiyatı tarihlerinin bambaşka yöntem ve üsluplarla zenginleşerek çoğalacağı ise ufukta görünüyor. Tanpınar'ın söylediği gibi “Modern Türk edebiyatı bir medeniyet kriziyle başlar." Bu kriz kültür, edebiyat ve dille en başından beri entegredir ve Tanzimat dönemiyle tempo arttırdığ 1 fark edilebilir. Alanında uzman akademisyenler tarafından kaleme alınan Modern Türk Edebiyatı da bir medeniyet kriziyle başlayıp günümüze dek uzanır. Nihayet tutarlı bir referans kaynak olma özelliğini de kapsamında bulundurarak ilgili okurları belki bir dahaki edebi hamleye dek bekliyor görünmektedir. 